EESTI NSV TEADUSTE AKADEEMIA TOIMETISED. 28. KOIDE

FOOSIKA * MATEMAATIKA. 1979, NR. 1

ИЗВЕСТИЯ АКАДЕМИИ НАУК ЭСТОНСКОИ ССР. ТОМ 28 ФИЗИКА * МАТЕМАТИКА. 1979, № 1

удк 518.517 .949 .12

M. LEVIN

\title{
ON OPTIMAL RECOVERY OF FUNCTIONS SATISFYING GIVEN BOUNDARY CONDITIONS
}

(Presented by A. Humal)

Let $W^{r} L_{q}$ be the set of all functions $f(x)$ satisfying conditions:

1. $f^{(r-1)}(x)$ is absolutely continuous on $[0,1]$,

2. $\left\|f^{(r)}(t)\right\|_{q}= \begin{cases}\left(\int_{0}^{1}\left|f^{(r)}(t)\right|^{q} d t\right)^{1 / q} \leqslant 1, & 1 \leqslant q<\infty, \\ \underset{0}{\operatorname{supvrai}}\left|f^{(r)}(t)\right| \leqslant 1, & q=\infty .\end{cases}$

We denote by $W_{U}^{r} L_{q}$ the set of all functions $f(x)$ belonging to $W^{r} L_{q}$ and satisfying

$$
U_{i}(f)=0 \quad(i=1, \ldots, s),
$$

where $0 \leqslant s \leqslant 2 r$ is given,

$$
U_{i}(f)=\sum_{j=0}^{r-1}\left[\alpha_{i j} f^{(j)}(0)+\beta_{i j} f^{(j)}(1)\right] \quad(i=1, \ldots, s)
$$

are given linearly independent functionals.

If $s=0$, then sets $W^{r} L_{q}$ and $W_{U}^{r} L_{q}$ coincide.

Consider the problem of constructing an optimal formula

$$
f(x)=\sum_{k=1}^{n} \sum_{j \in J_{k}} A_{k j} f^{(j)}\left(x_{k}\right)+R(f ; x),
$$

where $0 \leqslant x_{1}<\ldots<x_{n} \leqslant 1$. The sets $J_{k} \subseteq J=\{0,1, \ldots, r-1\}, k=1, \ldots$ $\ldots, n$, are given.

This problem is considered in some papers, e. g. $\left[{ }^{1-3}\right]$, for the set $W^{r} L_{q}$. Denote

$$
\begin{gathered}
R(x)=\sup _{f \in W_{U}^{r} L_{q}}|R(f ; x)|, \\
R=\|R(x)\|_{p_{1}} \quad\left(1 \leqslant p_{1}<\infty\right) .
\end{gathered}
$$

The formula (2) is called the best formula among formulas (2) with fixed nodes $x_{1}, \ldots, x_{n}$ and given $x \in(0,1)$ for $W_{U}^{r} L_{q}$, if its coefficients $A_{k j}=A_{k j}(x) \quad\left(k=1, \ldots, n ; j \in J_{k}\right)$ are chosen so that the quantity (3) has the least value. 
The formula (2) is called the optimal formula for $W_{U}^{r} L_{q}$, if its nodes $x_{k}$ and coefficients $A_{k j}=A_{k j}(x) \quad\left(k=1, \ldots, n ; j \in J_{k}\right)$ are chosen so that the quantity (4) is of least value.

We use the following notation:

Let

$$
V_{i}(g)=0 \quad(i=1, \ldots, 2 r-s)
$$

be boundary conditions adjoint (see [ $\left.{ }^{4}\right]$ ) of conditions (1); $P_{r-1}$ denotes the set of all polynomials of the degree $\leqslant r-1 ; \pi_{r-1}(U)$ is the set of all polynomials $\pi_{r-1}(x) \in P_{r-1}$ satisfying conditions $U_{i}\left(\pi_{r-1}\right)=0(i=1, \ldots, s)$; $\pi_{r-1}(V)$ is the set of all polynomials $\pi_{r-1}(x) \in P_{r-1}$ satisfying $V_{i}\left(\pi_{r-1}\right)=0$ $(i=1, \ldots, 2 r-s) ; Q_{r}(U)$ is the set of all formulas (2) with given $n, x$ and finite value $(3)$;

$K_{r}(V)$ is the set of splines (provided $x$ is given)

$$
K_{x}(t)=\varphi_{x}(t)+\sum_{j=0}^{r-1} c_{0 j} t^{j}+\sum_{k=1}^{n} \sum_{j \in J_{k}} c_{k j}\left(t-x_{k}\right)_{+}^{r-j-1}
$$

satisfying conditions

$$
\begin{gathered}
V_{i}\left(K_{x}\right)=0 \quad(i=1, \ldots, 2 r-s) \\
\varphi_{x}(t)=(t-x)_{+}^{r-1} /(r-1) ! \\
u_{+}^{j}=u^{j} \quad \text { if } u \geqslant 0, \quad u_{+}^{j}=0 \quad \text { if } \quad u<0
\end{gathered}
$$

$\hat{K}_{r}(V)$ is the quotient set $K_{r}(V) / \pi_{r-1}(V) ; \quad p^{-1}+q^{-1}=1$.

We mention that if formula (2) has a finite value (3), then by [5]

$$
\pi_{r-1}(x)=\sum_{k=1}^{n} \sum_{j \in J_{k}} A_{k j}(x) \pi_{r-1}^{(j)}\left(x_{k}\right)
$$

for any $\pi_{r-1}(x) \in \pi_{r-1}(U)$.

Let $K_{x}(t)$ be a spline (5) satisfying conditions $(6), f(x) \in W_{U}^{r} L_{q}$. Integrating by parts in the right side of equality

$$
\int_{0}^{1} f^{(r)}(t) K_{x}(t) d t=\sum_{k=0}^{n} \int_{x_{k}}^{x_{k+1}} f^{(r)}(t) K_{x}(t) d t,
$$

where $x_{0}=0, x_{n+1}=1$, gives

$$
\begin{gathered}
f(x)=\sum_{k=1}^{n} \sum_{j \in J_{k}}(-1)^{j} f^{(j)}\left(x_{k}\right)\left[K_{x}^{(r-j-1)}\left(x_{k}-0\right)-\right. \\
\left.-K_{x}^{(r-j-1)}\left(x_{k}+0\right)\right]+(-1)^{r} \int_{0}^{1} f^{(r)}(t) K_{x}(t) d t .
\end{gathered}
$$

Taking this into account and repeating the arguments of prooving the theorem 1 in $\left[{ }^{6}\right]$, we obtain the following result:

Theorem 1. The sets $Q_{r}(U)$ and $\hat{K}_{r}(V)$ are isomorphic. For any formula from $Q_{r}(U)$ and for $f(x) \in W_{U}^{r} L_{q}$ :

$$
\begin{gathered}
A_{k j}(x)=(-1){ }^{j}\left[K_{x}^{(r-j-1)}\left(x_{k}-0\right)-K_{x}^{(r-j-1)}\left(x_{k}+0\right)\right] \\
\left(k=1, \ldots, n ; j \in J_{k}\right),
\end{gathered}
$$




$$
\begin{aligned}
& R(f ; x)=(-1)^{r} \int_{0}^{1} f^{(r)}(t) K_{x}(t) d t, \\
& \sup _{f \in W_{U}^{r} L_{q}}|R(f ; x)|=\min _{K_{x}(t) \in \bar{K}}\left\|K_{x}(t)\right\|_{p},
\end{aligned}
$$

where $\bar{K}$ is the element from $\hat{K}_{r}(V)$ corresponding to considered formula from $Q_{r}(U), K_{x}(t)$ is an arbitrary spline from $\bar{K}$.

Below we consider formulas

$$
f(x)=\sum_{k=1}^{n} \sum_{j=0}^{r-1} A_{k j}(x) f^{(j)}\left(x_{k}\right)+R(f ; x)
$$

and the set $W_{I_{0} I_{1}}^{r} L_{q}(1<q \leqslant \infty)$ of functions $f(x)$ belonging to $W^{r} L_{q}$ and satisfying conditions

$$
f^{(i)}(0)=0 \quad\left(i \in I_{0}\right), \quad f^{(j)}(1)=0 \quad\left(j \in I_{1}\right),
$$

where $I_{0}, I_{1} \subseteq\{0,1, \ldots, r-1\}$ are given.

The adjoint boundary conditions of conditions (9) are

$$
g^{(i)}(0)=0 \quad\left(i \in I_{0}^{c}\right), \quad g^{(j)}(1)=0 \quad\left(j \in I_{1}^{c}\right),
$$

where $I_{k}^{c}=\left\{i: i \in\{0,1, \ldots, r-1\}, r-i-1 \notin I_{k}\right\}, k=0,1$.

Splines (5), provided $J_{k}=\{0,1, \ldots, r-1\}, k=1, \ldots, n$, satisfying conditions (10) are of the form:

1. If $0<x<x_{1}$, then

$$
K_{x}(t)=\left\{\begin{array}{c}
\varphi_{x}(t)-\sum_{j \in I_{0}} c_{0 j} t^{r-j-1}, \quad t \in\left[0, x_{1}\right), \\
p_{0 i}(t), \quad t \in\left[x_{i}, x_{i+1}\right), \quad i=1, \ldots, n, \\
p_{0 n}^{(j)}(1)=0 \quad\left(j \in I_{1}^{c}\right) ;
\end{array}\right.
$$

2. If $x_{l}<x<x_{l+1}(l=1, \ldots, n-1)$, then

$$
\begin{gathered}
K_{x}(t)=\left\{\begin{array}{l}
p_{l i}(t), t \in\left[x_{i}, x_{i+1}\right), i \neq l, \\
\varphi_{x}(t)-p_{l l}(t), t \in\left[x_{l}, x_{l+1}\right),
\end{array}\right. \\
p_{l 0}^{(j)}(0)=0 \quad\left(j \in I_{0}^{c}\right), p_{l n}^{(j)}(1)=0 \quad\left(j \in I_{1}^{c}\right) ;
\end{gathered}
$$

3. If $x_{n}<x<1$, then

$$
\begin{aligned}
& K_{x}(t)=\left\{\begin{array}{l}
p_{n i}(t), t \in\left[x_{i}, x_{i+1}\right), i \neq n, \\
(-1)^{r}(x-t)_{+}^{r-1} /(r-1) !-\sum_{j \in I_{1}} c_{n j}(t-1)^{r-j-1}, \quad t \in\left[x_{n}, 1\right],
\end{array}\right. \\
& p_{n 0}^{(j)}(0)=0 \quad\left(j \in I_{0}^{c}\right),
\end{aligned}
$$

where $p_{i k}$ are polynomials of the degree $\leqslant r-1$.

By theorem 1 and formula (7) it is sufficient to choose the spline $K_{x}^{*}(t)$ of least norm in $L_{p}(0,1)$ among above described splines for constructing the best formula (8) for the set $W_{I_{0} I_{1}}^{r} L_{q}$.

It is easy to verify that 


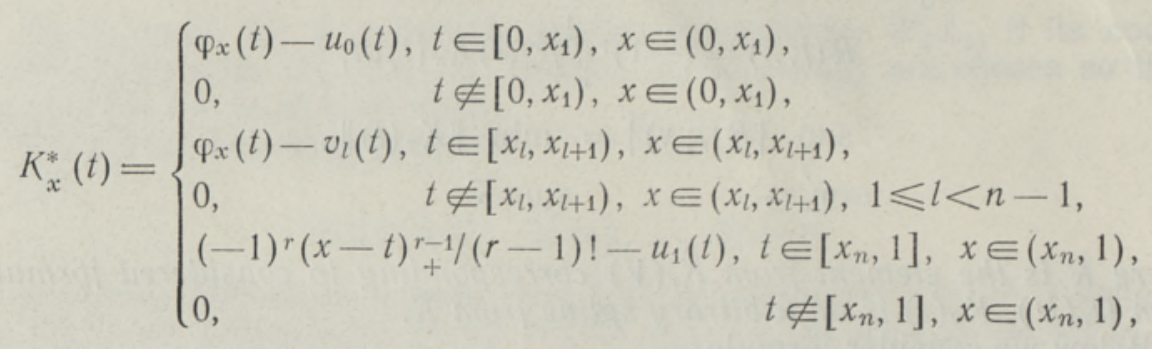

where $u_{0}(t)$ is the polynomial of the form $\sum_{j \in I_{0}} c_{0 j} t^{r-j-1}$ and of least deviation from $\varphi_{x}(t)$ in $L_{p}\left(0, x_{1}\right), v_{l}(t)$ is the polynomial of the degree $\leqslant r-1$ and of least deviation from $\varphi_{x}(t)$ in $L_{p}\left(x_{l}, x_{l+1}\right), u_{1}(t)$ is of the form $\sum_{j \in I_{1}} c_{n j}(\mathrm{t}-1)^{r-j-1}$ and of least deviation from $(-1)^{r}(x-t)_{+}^{r-1} /(r-1)$ ! in $L_{p}\left(x_{n}, 1\right)$.

Applying this, theorem 1 and (7), we obtain

Theorem 2. The best formula (8) for the set $W_{I_{0} I_{1}}^{r} L_{q}$ provided $x \in\left(x_{l}, x_{l+1}\right)(l=0,1, \ldots, n)$ is

$$
f(x)=\sum_{j=0}^{r-1}\left[A_{l j} f^{(j)}\left(x_{l}\right)+B_{l j} f^{(j)}\left(x_{l+1}\right)\right]+R(f ; x),
$$

where

$$
\begin{aligned}
A_{0 j} & =0 \\
B_{0 j} & =\frac{\left(x-x_{1}\right)^{j}}{j !}-(-1)^{j} u_{0}^{(r-j-1)}\left(x_{1}\right), \\
A_{l j} & =(-1)^{j} v_{l}^{(r-j-1)}\left(x_{l}\right) \\
B_{l j} & =\frac{\left(x-x_{l+1}\right)^{j}}{j !}-(-1)^{j} v_{l}^{(r-j-1)}\left(x_{l+1}\right), l=1, \ldots, n-1, \\
A_{n j} & =\frac{\left(x-x_{n}\right)^{j}}{j !}+(-1)^{j} u_{1}^{(r-j-1)}\left(x_{n}\right), \\
B_{n j} & =0, \quad j=0, \ldots, r-1 .
\end{aligned}
$$

For this:

$$
R(x)=\left\{\begin{array}{l}
\left\|\varphi_{x}(t)-u_{0}(t)\right\|_{L_{p}\left(0, x_{1}\right)}, \quad x \in\left(0, x_{1}\right), \\
\left\|\varphi_{x}(t)-v_{l}(t)\right\|_{L_{p}\left(x_{l}, x_{l+1}\right)}, \quad x \in\left(x_{l}, x_{l+1}\right), \quad l=1, \ldots, n-1, \\
\left\|(-1)^{r}(x-t)_{+}^{r-1} /(r-1) !-u_{1}(t)\right\|_{L_{p}\left(x_{n}, 1\right)} \quad x \in\left(x_{n}, 1\right) .
\end{array}\right.
$$

Here the notation

$$
\|f(t)\|_{L_{p}(\alpha, \beta)}=\left(\int_{\alpha}^{\beta}|f(t)|^{p} d t\right)^{1 / p}
$$

is used.

The corresponding result from the paper $\left[{ }^{1}\right]$ for the set $W^{r} L_{q}$ is a particular case of theorem 2 , if we take there $I_{0}=I_{1}=\varnothing$. A similar result for 1-periodical functions from $W^{r} L_{\infty}$ is obtained in $\left[{ }^{7}\right]$. 
Consider the problem of the optimal choice of the nodes of the formula (8). For this we investigate the error $R(x)$ obtained in theorem 2.

Introduce the following notation:

$u_{0}(t, y)$ is the function which for every fixed $y \in[0,1]$ is a polynomial of the form $\sum_{j \in I_{0}} a_{j} t^{r-j-1}$ and of least deviation from $\varphi_{y}(t)$ in $L_{p}(0,1)$;

$v(t, y)$ is the function which for every fixed $y \in[0,1]$ is a polynomial of the degree $\leqslant r-1$ and of least deviation from $\varphi_{y}(t)$ in $L_{p}(0,1)$;

$u_{1}(t, y)$ is the function which for every fixed $y \in[0,1]$ is a polynomial $\sum a_{j}(t-1)^{r-j-1}$ of least deviation from $(-1)^{r}(y-t)_{+}^{r-1} /(r-1) !$ in $L_{p}(0,1)$

$$
\begin{gathered}
h_{l}=x_{l+1}-x_{l}, l=1, \ldots, n-1 ; p_{2}=p_{1} / p \\
\delta=\left[\int_{0}^{1}\left(\int_{0}^{1}\left|\varphi_{y}(t)-u_{0}(t, y)\right|^{p} d t\right)^{p_{2}} d y\right]^{1 / p_{1}} \\
\varrho=\left[\int_{0}^{1}\left(\int_{0}^{1}\left|\varphi_{y}(t)-v(t, y)\right|^{p} d t\right)^{p_{2}} d y\right]^{1 / p_{1}} ; \\
\sigma=\left[\int_{0}^{1}\left(\int_{0}^{1}\left|(-1)^{r} \frac{(y-t)_{+}^{r-1}}{(r-1) !}-u_{1}(t, y)\right|^{p} d t\right)^{p_{z}} d y\right]^{1 / p_{1}}
\end{gathered}
$$

In virtue of change of the variables, we justify that the quantity (4) for the function $R(x)$ from theorem 2 can be written as

$$
R=\left(x_{1}^{v} \delta^{p_{1}}+Q^{p_{t}} \sum_{l=1}^{n-1} h_{l}^{v}+\left(1-x_{n}\right)^{v} \sigma^{p_{1}}\right)^{1 / p_{l}},
$$

where $v=(r-1) p_{1}+p_{2}+1$.

Thus the optimal formula (8) for the set $W_{I_{0} I_{1}}^{r} L_{q}$ has nodes for which (11) is of least value. It is easy to find such nodes. They are

$$
x_{k}=\left[\left(\frac{\varrho}{\delta}\right)^{\frac{1}{r-1+1 / p}}+k-1\right] h, \quad k=1, \ldots, n,
$$

where

$$
h=\left[n-1+\left(\frac{\varrho}{\delta}\right)^{\frac{1}{r-1+1 / p}}+\left(\frac{\varrho}{\sigma}\right)^{\frac{1}{r-1+1 / p}}\right]^{-1} .
$$

The quantity (11), provided the nodes are equal to (12), is equal to

$$
R=\mathrm{Q} h^{r-1+1 / p} \text {. }
$$

Therefore we have

Theorem 3. The optimal formula (8) for $W_{I_{0} I_{1}}^{r} L_{q}$ has nodes (12) and coefficients defined in theorem 2. For this formula the quality (4) is equal to (13).

We can notice that applying the limit process $p \rightarrow \infty$ one may prove theorem 3 in the case $p_{1}=\infty$, too.

In a particular case $p_{1}=\infty, I_{0}=I_{1}=\varnothing$ this theorem was obtained in paper $\left.{ }^{1}\right]$.

Denote by $W_{01}^{r} L_{q}$ the set $W_{I_{0} I_{1}}^{r} L_{q}$ with $I_{0}=I_{1}=\{0,1, \ldots, r-1\}$. 
We have no difficulty noticing that $\delta=\sigma=\mathrm{Q}$ in the case $I_{0}=I_{1}=$ $=\{0,1, \ldots, r-1\}$. This leads to

Theorem 4. The optimal formula (8) for the set $W_{01}^{r} L_{q}$ has nodes

$$
x_{k}=\frac{k}{n+1} \quad(k=1, \ldots, n)
$$

and estimate

$$
R=\frac{\varrho}{(n+1)^{r+1+1 / p}} .
$$

Remark. Similar results can be obtained for evaluation derivatives of $f(x)$, too.

As we saw above, the results on optimal recovery of functions are similar to the results on optimal quadrature formulas $\left[{ }^{6,8}\right]$. We can say the same about the two-dimensional case.

We shall give an example.

Suppose for $k=1,2$ the boundary value problems

$$
f^{\left(r_{k}\right)}(x)=0, \quad U_{i k}(f)=0 \quad\left(i=1, \ldots, r_{k}\right)
$$

have Green's function. Let $W_{U^{k}}^{r_{k}} L_{2}$ be the set of functions $f(x)$ belonging to $W^{r_{k}} L_{2}$ and satisfying conditions $U_{i k}(f)=0\left(i=1, \ldots, r_{k}\right)$. Let, further, $W_{U U^{1}(1,2)}^{r^{1}, L_{2}^{2}} L_{2}$ be the set of functions $h(x, y)$ which have piecewise continuous derivatives

$$
h^{(j, l)}(x, y)=\frac{\partial^{j+l}}{\partial x^{j} \partial y^{l}} h(x, y) \quad\left(j=0, \ldots, r_{1} ; l=0, \ldots, r_{2}\right)
$$

on $D=[0,1] \times[0,1]$ and satisfy conditions

$U_{i 1}(h(\cdot, y)) \equiv 0 \quad\left(i=1, \ldots, r_{1}\right), \quad U_{i 2}(h(x, \cdot)) \equiv 0 \quad\left(i=1, \ldots, r_{2}\right)$,

$$
\left\|h^{\left(r_{1}, r_{2}\right)}(x, y)\right\|_{L_{2}(D)} \leqslant 1 \text {. }
$$

The formula

$$
h(x, y)=\sum_{i=1}^{n_{1}} \sum_{k=1}^{n_{2}} \sum_{j \in J_{t}} \sum_{l \in L_{k}} A_{i k}^{j l} f^{(j, l)}\left(x_{i}, y_{k}\right)+R(h ; x, y)
$$

is called the optimal formula for the set $H$ of functions $h(x, y)$ if its nodes $\left(x_{i}, y_{k}\right)$ and coefficients $A_{i k}^{j l}$ are chosen so that the quantity

$$
R=\left\|\sup _{h \in H}|R(h ; x, y)|\right\|_{L_{2}(D)}
$$

is of least value.

Let $J_{i} \subseteq\left\{0,1, \ldots, r_{1}-1\right\}, \quad L_{k} \subseteq\left\{0,1, \ldots, r_{2}-1\right\} \quad\left(i=1, \ldots, n_{1}\right.$; $\left.k=1, \ldots, n_{2}\right), p_{1}=2$. Suppose then $x_{k}^{*}, A_{k j}^{*}\left(k=1, \ldots, n_{1} ; j \in J_{k}\right)$, $R_{1}$ are nodes, coefficients and value (4) of the optimal formula (2) with $n=n_{1}$ for $W_{U^{\prime}}^{r_{1}} L_{2}$. Let $y_{k}^{*}, B_{k j}^{*}\left(k=1, \ldots, n_{2} ; j \in L_{j}\right), R_{2}$ be nodes, coefficients and value (4) of the optimal formula (2) (where we change $n$ by $n_{2}, J_{k}$ by $\left.L_{k}\right)$ for $W_{U^{2}}^{r_{2}} L_{2}$.

One can prove the following statement in a manner analogous to the way we used in $\left[{ }^{9}\right]$ : 
Theor e m. 5. The optimal formula (16) for the set $W_{U(1,2)}^{r_{1}, r_{2}} L_{2}$ has nodes and coefficients

$$
\begin{gathered}
\left(x_{i}, y_{k}\right)=\left(x_{i}^{*}, y_{k}^{*}\right), \quad A_{i k}^{j l}=A_{i j}^{*} B_{k l}^{*} \\
\left(i=1, \ldots, n_{1} ; \quad k=1, \ldots, n_{2} ; \quad j \in J_{i} ; \quad l \in L_{k}\right)
\end{gathered}
$$

and estimate

where

$$
R=\left(R_{1}^{2} g_{2}+R_{2}^{2} g_{1}-R_{1}^{2} R_{2}^{2}\right)^{1 / 2}
$$

$$
g_{k}=\int_{0}^{1} \int_{0}^{1} G_{k}^{2}(x, y) d x d y, \quad k=1,2
$$

$G_{k}(x, y)$ is the Green's function for the problem (14).

In the same way one can extend another results to the formula (16), e. g. results similar to those obtained in papers [ ${ }^{10,11}$ ].

\section{REFERENCES}

1. В о j nov, В. D., Докл. Болг. АH, 27, № 7, 885-888 (1974).

2. Micchelli, C. A., Rivlin, T. J., Winograd, S., Numer. Math., 26, № 4, $191-200(1976)$.

3. Optimal estimation in approximation theory (Ed. by C. A. Micchelli and T. J. Rivlin), New York-London, Plenum Press, 1976.

4. Н а йм а р к М. А., Линейные дифференциальные операторы, М., «Наука», 1969.

5. Л е в и н М., Изв. АН ЭССР, Физ. Матем., 20, № 1, 90-91 (1971).

6. Г и ршов и ч Ю. М., Л в ин М. И., Тр. Таллинск. политехн. ин-та, сер. А, № 393, $21-30$ (1976).

7. Forst, W., J. Approxim. Theory, 20, № 4, 333-347 (1977).

8. Н и коль с к и й С. М., Квадратурные формулы, М., «Наука», 1974.

9. Л е в и н М., Изв. АН ЭССР, Физ. Матем., 25, № 4, 331-337 (1976)

10. Girshovich, Y., Levin, M., ENSV TA Toim., Füüs. Matem., 27, № 2, 151-158 (1978).

11. Левин М. И., Гиршович Ю. М., Докл. АН СССР, 236, № 6, 1303-1306 (1977).

Tallinn Polytechnic Institute

Received

February 20, 1978

M. LEVIN

\section{ANTUD RAJATINGIMUSI RAHULDAVATE FUNKTSIOONIDE PARIMATEST TAASTAMISVALEMITEST}

On vaadeldud parimate valemite (2), s. o. vähima väärtusega (3) ( $x$ on fikseeritud) ja vähima väärtusega (4) ( $x$ on suvaline) leidmist funktsioonide $f(x)$ hulgal $W_{U^{r}} L_{q}$, mis rahuldavad tingimusi $\left\|f^{(r)}\right\|_{L_{q}(0,1)} \leqslant 1$ ja (1). Teisel juhul on otsitud nii sõlmi kui ka kaale. On leitud seos püstitatud ülesande lahendi ja tingimuste (6) kaastingimusi (1) rahuldavate splainide (5) vahel.

Valemile (8) ja hulgale $W_{U}^{r} L_{q}$, kus $U_{i}(f)$ on määratud avaldisega (9), on leitud sõlmed, kaalud ja parima valemi jäägi hinnang. Saadud tulemused on üldistatud ka kahemõõtmelisele juhule. Näitena on vaadeldud parimat valemit (16) (vähima väärtusega (17)) funktsioonide $h(x, y)$ hulgal, mis rahuldavad piirkonnas $D=[0,1] \times[0,1]$ tingimusi (15). 
M. ЛЕВНH

\section{О НАИЛУЧШИХ ФОРМУЛАХ ВОССТАНОВЛЕНИЯ ДЛЯ ФУНКЦИИ, УДОВЛЕТВОРЯЮЩИХ ЗАДАННЫМ КРАЕВЫМ УСЛОВИЯМ}

Пусть $W_{U}^{r} L_{q}-$ множество функций $f(x) \in W^{r} L_{q}$ и удовлетворяющих линейно-независимым краевым условиям $U_{i}(f)=0(i=1, \ldots, s)$ на отрезке $[0,1]$. Рассматривается задача построения на этом множестве наилучшей формулы

$$
f(x)=\sum_{k=1}^{n} \sum_{j \in J_{k}} A_{k j}(x) f^{(j)}\left(x_{k}\right)+R(f ; x),
$$

т. е. форхулы с наихеньшим значением величины

$$
\left\|\sup _{f \in W_{U}^{r} L_{q}} \mid R(f ; x)\right\|_{L_{p_{1}}(0,1)} .
$$

Изучается связь между сплайнами и решением этой задачи. Для случаев $J_{k}=$ $=\{0,1, \ldots, r-1\} \quad(k=1, \ldots, n)$ и $U_{i}(f)=f^{(i)}(0) \quad\left(i \in I_{0}\right), U_{i}(f)=f^{(i)}(1) \quad\left(i \in I_{1}\right)$, $I_{0}, I_{1} \subseteq\{0, \ldots, r-1\}$ находятся узлы, веса и оценка остатка наилучшей формулы. В случае $I_{0}=I_{1}=\{0, \ldots, r-1\}$ эти узлы имеют вид

$$
x_{k}=k /(n+1) \quad(k=1, \ldots, n) \text {. }
$$

Показывается, как полученные результаты могут быть распространены на двумерный случай. 